\title{
Erratum
}

\section{Characterization of MOVPE-Grown GaAs Layers by C-V Analysis}

\section{T. Paskova, R. Yakimova, E. Valcheva, K. Germanova}

Appl. Phys. A 56, 69-72 (1993)

Due to a printing error the figure caption to Fig. 2 was incorrect and should read

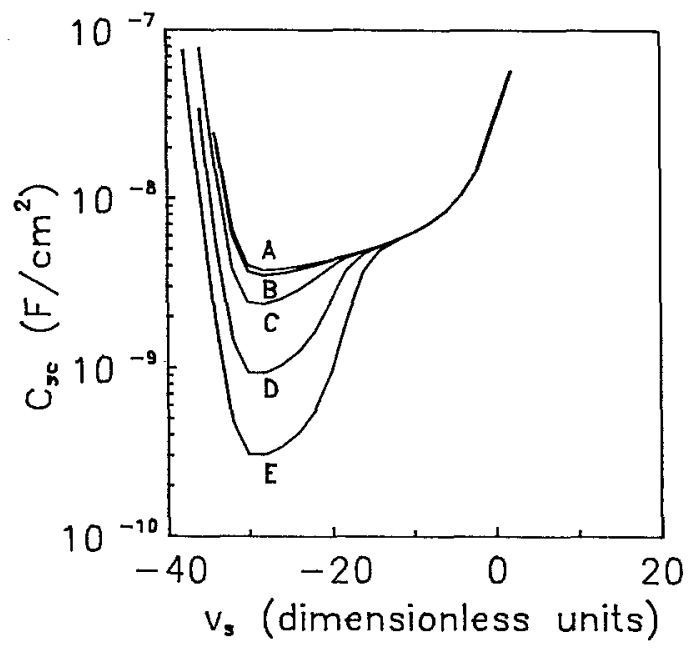

Fig. 2. The capacitance $C_{\mathrm{sc}}$ as a function of the surface potential $v_{\mathrm{s}}$ in the SCL of $n$-type GaAs epitaxial layer; $N_{\text {sd }}-N_{\text {sa }}=1 \times 10^{14} \mathrm{~cm}^{-3}$, $N_{\text {dd }}\left[\mathrm{cm}^{-3}\right]=\left(A: 0, B: 5 \times 10^{13}, C: 5 \times 10^{14}, D: 5 \times 10^{15}, E: 5 \times 10^{16}\right)$ 